\title{
Assessment of stress distribution in ankle joint: simultaneous application of experimental and finite element methods
}

\author{
Ahmad Chitsazan and Gholamreza Rouhi* \\ Faculty of Biomedical Engineering, \\ Amirkabir University of Technology, \\ 424 Hafez Avenue, Tehran 15914, Iran \\ Email: a.chitsazan@aut.ac.ir \\ Email: grouhi@aut.ac.ir \\ *Corresponding author

\section{Mostafa Abbasi} \\ Department of Mechanical and Materials Engineering, \\ University of Denver, \\ Denver, USA \\ Email: mostafa.abbasi@du.edu
}

\section{Saeid Pezeshki}

Faculty of Medical Sciences,

Islamic Azad University of Tehran,

Tehran, Iran

Email: dr.pezeshki.ortho@gmail.com

\author{
Seyed Amir Hossein Tavakoli \\ Iranian Tissue Bank Research and Preparation Centre, \\ Tehran, Iran \\ Email: amirtavakoli1@yahoo.com
}

\begin{abstract}
The goal of this study was to determine stress distribution in ankle joint by correlating with the strain distribution and its trend around tibia adjacent to the joint. Using an in-house device, an ankle from a cadaver was kept stable and loaded in various positions: neutral, dorsiflexion, plantar flexion, inversion and eversion. A total of six strain gauges were mounted around the shaft of the tibia, near the tibiotalar joint. This arrangement allowed us to measure deformations in the shaft of tibia. Patient-specific ankle joint geometry was generated from computed tomography data. The finite element model (FEM) of the ankle was validated using the experimental data logged by the strain gauges, and used for obtaining stress on the joint surface. A strong correlation was observed between the FEM and experimentally measured strains in magnitude $(\mathrm{R}=0.94, \mathrm{P}=0.008)$, consequently stress distribution over the joint surface was obtained.
\end{abstract}


Keywords: ankle joint; strain gauge; experimental and computational; stress distribution; finite element analysis; contact stress.

Reference to this paper should be made as follows: Chitsazan, A., Rouhi, G., Abbasi, M., Pezeshki, S. and Tavakoli, S.A.H. (2015) 'Assessment of stress distribution in ankle joint: simultaneous application of experimental and finite element methods', Int. J. Experimental and Computational Biomechanics, Vol. 3, No. 1, pp.45-61.

Biographical notes: Ahmad Chitsazan is a Research Assistant at Orthopaedic and Dental Biomechanics Laboratory (ODBL). The ODBL is a group of scientists and engineers interested in diseases and disorders relating to bone mechanics, human joint mechanisms, and effective treatment strategies for bone and joint disorders caused by arthritis, osteoporosis, trauma and other related problems. He graduated in Biomedical Engineering, major in Sports Biomechanics from Tehran Polytechnic University in 2012. His research interests include studying the orthopaedic biomechanics, bone mechanics, bone modelling and joint biomechanics as they relate to the developing field of prosthetic joint and patient specific computer-aided surgery. He is involved in research consist of mechanical testing methods and finite element analysis on bone and joint.

Gholamreza Rouhi received his BSc and MSc degrees from Sharif University of Technology, Iran. He was awarded his $\mathrm{PhD}$ in Mechanical Engineering, major in Biomechanics, from the University of Calgary for his investigations on bone remodelling and resorption theories. After earning his $\mathrm{PhD}$ degree, he started his new career as an Assistant Professor in Mechanical Engineering at the University of Ottawa. He then moved back to Iran and was recruited by Amirkabir University of Technology. He is involved in various projects including: bone fracture healing; bone remodelling theories; bone-implants interaction; orthopaedic implants and prostheses; biomechanics of articular cartilage; and synovial joints biomechanics.

Mostafa Abbasi received his BSc and MS in Mechanical Engineering, major in Solid Mechanics, both from Amirkabir University of Technology, Tehran Polytechnic. His research interests focused on computational solid mechanics, biomechanics and applied mathematics, including the theory and applications of the finite element method. Since 2014, he has started his $\mathrm{PhD}$ as a Research Assistant in the Cardiac Biomechanics Laboratory at the University of Denver. His current research focuses on applied research in cardiovascular diseases to develop new therapeutic and diagnostic devices such as bioprosthetic aortic valves.

Saeid Pezeshki received his Orthopedic Board at Yazd Medical School in 1997. $\mathrm{He}$ is an Assistant Professor at Azad University of Tehran, Medical Branch since 2003. His research is focused on orthopedic disease and bio mechanics.

Seyed Amir Hossein Tavakoli received his General Practitioner (MD) in Tehran University of Medical Science (TUMS) in 1998, and graduated in Psychiatry in 2004 from Iran University of Medical Science. He is an Assistant Professor of Iranian Tissue Bank Research Center and he had experience in tissue banking organ transplant procurement management. Since 1998, his activity and research is focused on allograft-based products.

This paper is a revised and expanded version of a paper entitled 'Strain distribution on tibia surface during gait cycle: experimental investigations' presented at 17 th Biennial Meeting of the Canadian Society of Biomechanics, CSB2012, Simon Fraser University Vancouver, BC, Canada, 6-9 June 2012. 


\section{Introduction}

The ankle is a complex joint in human body. It includes the tibia, fibula, and talus in a mortise-like joint compartment. Multiple bones, each with unique interactions, associate in a specific manner to make movement of the hind foot. The articular cartilage layer and synovial fluid, which are surrounded by the joint capsule, have important role under impact loading and in high stress conditions (Greene et al., 2008; Caligaris and Ateshian, 2008; Ateshian, 2009). The joint capsule and ligaments provide stability to the joint. Determination of contact area between these ankle joint components as a function of loading, ankle position, and stability, is crucial for understanding the pathogenesis of ankle disorders, such as degenerative arthrosis amongst other ankle abnormalities (Hideji et al., 1998). In order to measure contact pressures, most studies used pressure-sensitive film, or pressure transducers mounted at or below the joint surface (Beaudoin et al., 1991; Anderson et al., 2007; Michael et al., 2008). In some studies, finite element method was used and validated by comparing the computed pressure distribution with those derived by various experimental methods (Anderson et al., 2007). Magnetic resonance imaging (MRI) and CT data, which are used for generating finite element modes (FEMs), can facilitate pre-operative planning in many surgeries (Arbabi et al., 2007; Gilles et al., 2006; Ringleb et al., 2005).

Despite the current use of FEM for simulation of joints, such as hip and knee, its use has been less frequent for the study of multi-bone joints, such as the ankle or wrist. Multi-bone joints pose the problem of involving complex boundary conditions and constraints, hence making it difficult to be resolved by FEMs. Consequently, almost all studies involving these complex joints have been based on experimental methods by applying uni-axial compressive loads, and employing pressure sensitive films for recording the data, to evaluate stress distributions from the joint surface of cadavers (Gíslason et al., 2010; Von Eisenhart-Rothe et al., 1997). In recent years, reverse dynamics formulations have been used to calculate joint reaction forces (Alkjaer et al., 2001; Brand et al., 1994). Even though forces and ranges of motion at the ankle joint can be determined using various biomechanical methods, a comprehensive solution for determining the stress distribution within this joint has not been proposed yet. In most studies, which consist of pressure sensitive films or pressure transducers mounted at or below the joint (Anderson et al., 2007; McKinley et al., 2006), inherent limitations exist in these techniques, for example, crinkling artefacts caused by using the pressure sensitive film between curved joint surfaces (Hideji et al., 1998). Periarticular soft tissue dissection is also required for putting the film and transducers, which may alter the stability of the joint and soft tissue envelope (Anderson et al., 2007; Macirowski et al., 1994; Tochigi et al., 2006). Synovial fluid leakage in the joint region during the loading cycle may also occur, and it is known that pressure transducers only provide information for a limited region of the joint (Hideji et al., 1998; Anderson et al., 2007; McKinley et al., 2006). McKinley and co-workers used an experimental approach to measure transient contact stresses in human cadaveric ankles during quasi-physiologic motion. In this study loading was used to determine how step-off incongruities of the distal tibia affected contact stresses and contact stress gradients in the joint (McKinley et al., 2006). Inherent complexity of the ankle joint makes it difficult to validate FEMs (Gíslason et al., 2010). Goreham-Voss and co-workers (2007) investigated stress distribution over the articular surface of ankle joint using FEM, in which they validated their FE model with 
experimental data. Based on mechanical testing of long bones through mounting strain gauges on the cortical layer and measuring the strains, the linear bending theory is verified for tibia (Cordey and Gautier, 1999). It is known that under eccentric axial loading, the linear bending theory applies very well in long bones like tibia (Cordey and Gautier, 1999). In this case, an eccentric axial load can be considered equivalent as a load on the neutral axis, plus a pure bending moment. Therefore, position of the joint and its displacement determines the eccentricity and bending moment, so the bending strain may cause tension in one part (e.g., anterior side), and compression in the opposite part of the bone (Gilles et al., 2006; Cordey and Gautier, 1999; Yang et al., 2011). Therefore, due to complex geometry and contact between joints in ankle, combination of minimally invasive experimental and reliable computational methods is necessary to evaluate the contact pressure at the joint surface.

The main target of this study was to demonstrate a new low-invasive method for investigating tibiotalar joint contact features, such as contact surface status after loading and stress distribution on the joint surface. In order to do so, strain gauges data were employed to validate our FEM. The purpose was also to obtain strain distribution around the tibia adjacent to the ankle joint in different ankle positions, and to assess the path of load transmission through the joint.

\section{Methods}

A 3D FEM was made using CT data and validated by comparing the trends of strains collected by the strain gauges just in the neutral position of the foot. It should be noted that for all other positions of the foot, strain gauges data were collected. Figure 1 shows the work flow of this research, from experimental trial stain gauges to obtain stress distribution on the ankle joint surface using FEM.

\subsection{Experimental method}

A cadaver ankle, from a 46 year old male without joint disease, was used for mounting strain gauges. Unfreezing of the specimen from $-80^{\circ} \mathrm{C}$ to $-20^{\circ} \mathrm{C}$ took place within 24 hours, followed to room temperature in about 18 hours (Söderdahl et al., 1998). Soft tissues were carefully removed by an orthopaedic surgeon in order to keep intact the joint compartment and ligaments. Also, the periosteal layer was carefully removed and the mounting surface was dried out and prepared for attaching the strain gauges (see Figure 2). In order to have a strong attachment between bone and strain gauges, the oily layer under the periosteum was carefully removed using acetone. Since the fibula is not a crucial weight bearing component in the ankle [about $7 \%$ of the total force is transmitted through the fibula (Goh et al., 1992)], the tibiofibular joint was excluded from the loading procedure. This is done for increasing the accuracy of the results. 
Figure 1 Research workflow: iterative optimisation cycle lead FE model to meet criteria in strain data due to compare with experiment strain gauges data (using similarity in the magnitudes and distribution of strains with an acceptable correlation coefficient) (see online version for colours)

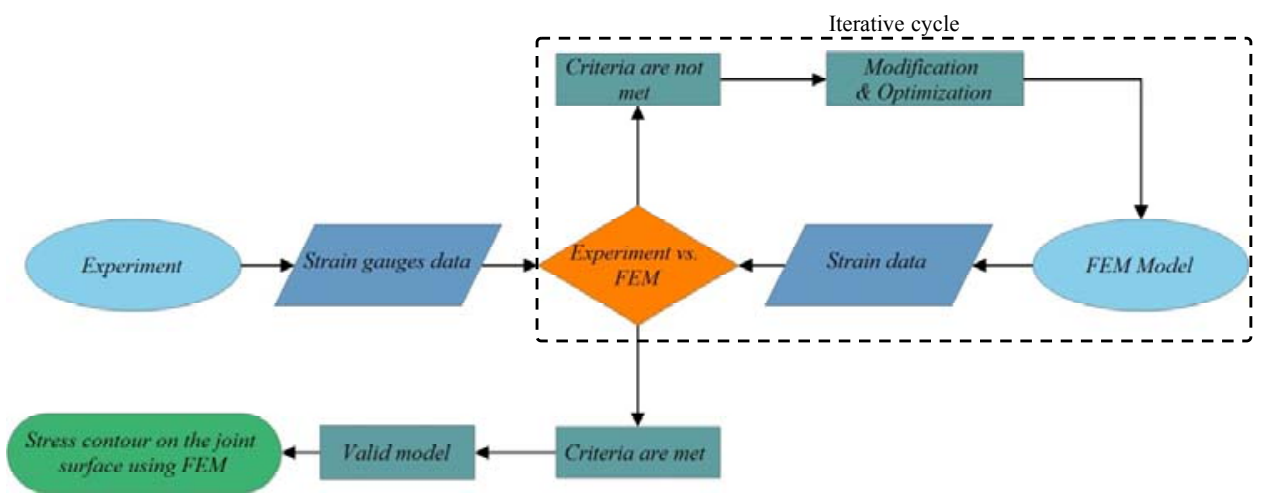

Note: Whereby stress distribution on the joint surface determined using validated computational model.

Figure 2 (a) Prepared bone for mounting strain gauges (shown in blue ellipses) (b) Arrows show two strain gauges on the anterior side, and one on the lateral side of tibia (see online version for colours)

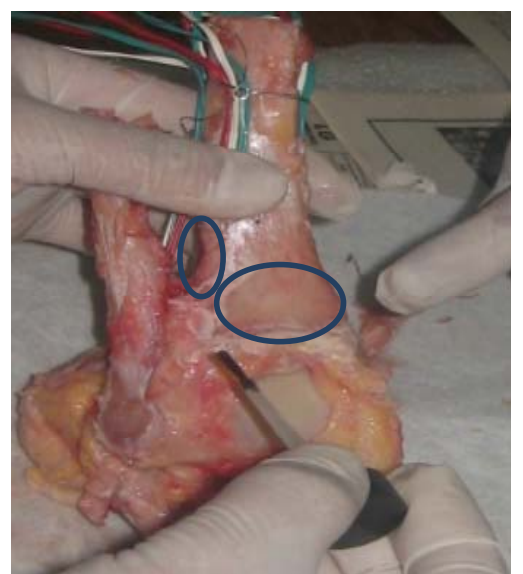

(a)

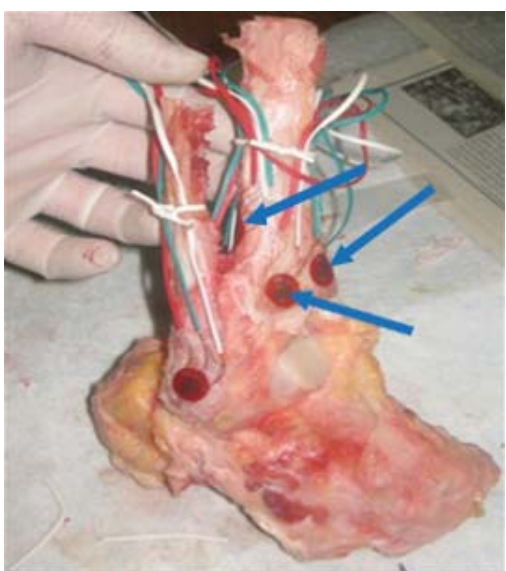

(b)

Notes: The periosteal layer was removed, and superficial contaminations were carefully eliminated by a powerful solvent.

Six strain gauge sensors (three axes TML, Tokyo Sokki Kenkyujo Co. Ltd. rosette strain gauge) were carefully mounted on the sub-layer of the periosteum of the tibia, on the intact cadaver foot. The strain gauges were arranged as follows: two on the anterior, two on the posterior, one on the medial, and one on the lateral side of the tibia (see Figures 2 and 3 ). Positions of the sensors were selected according to anatomical landmarks on the distal side of the tibia, the nearest place on the top of the joint capsule. The opposite strain gauges were placed at the same height on the anterior and posterior, as well as on 
the medial and lateral sides of the tibia. Also, for all sensors, the first axis, which is specified on the sensors, was placed along the tibia's longitudinal axis (see Figure 3).

Figure 3 Stain gauge arrangement on the distal region of the tibia (see online version for colours)

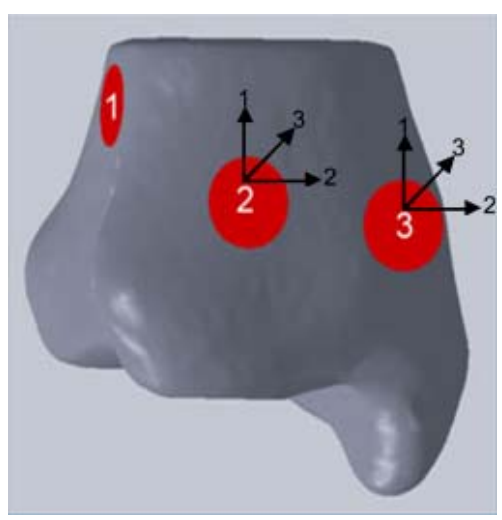

(a)

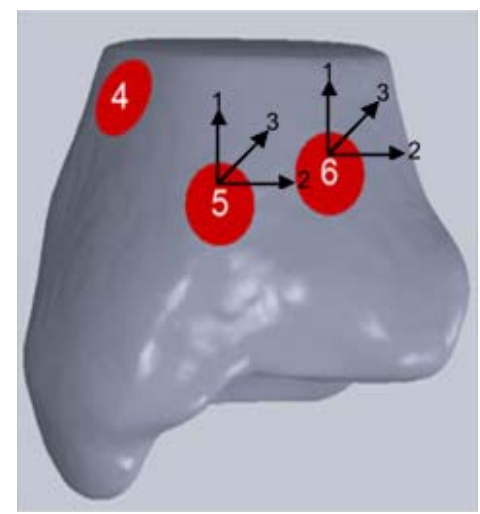

(b)

Notes: Sensors are attached near the joint surface on the shaft of the ankle.

1 - lateral; 2 - anterolateral; 3 - anteromedial; 4 -medial; 5 - posteromedial; 6 -posterolateral

Figure 4 Mechanism manufactured to keep the ankle joint fixed in various anatomical positions (see online version for colours)

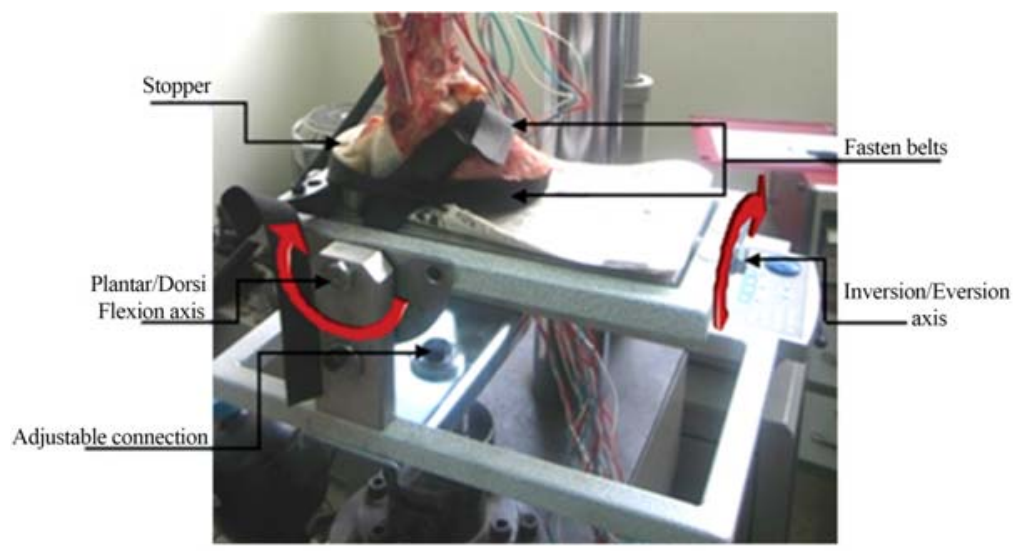

Note: Dorsi/plantar flexion, and inversion/eversion

The top surface of the tibia, wherein load was applied, was carefully flattened and prepared for axial load exertion. In order to be able to simulate various anatomical positions, the ankle joint was mounted on a specific fixture designed and manufactured for this study (Figure 4). This device allowed us to move the joint in various anatomical positions with two degrees of freedom, i.e. flexion $\left(30^{\circ}\right)$ /extension $\left(20^{\circ}\right)$, and inversion $\left(15^{\circ}\right)$ /eversion $\left(15^{\circ}\right)$ (Figure 4$)$. In order to precisely adjust the loading position, the device was equipped with a guide, in medial/lateral, or anterior/posterior directions. The external load was applied from the bottom of the foot, and increased from zero to $1,000 \mathrm{~N}$ 
in about 70 seconds, and then decreased gradually to $0 \mathrm{~N}$ with the same rate. Five different positions were carried out as follows: neutral position $\left(0^{\circ}\right)$, plantar flexion $\left(30^{\circ}\right)$, dorsi flexion $\left(20^{\circ}\right)$, inversion $\left(15^{\circ}\right)$, and eversion $\left(15^{\circ}\right)$. Strain gauges data were collected during the specified time intervals simultaneously from all axes, and then compared between various joint angles. The fasten belts (Figure 4) were used to adjust the axis of loading (upward) with respect to the axis of support, and keep the underfoot surface immovable and flat during the load exertion.

TML, TDS 602 strain data logger was used, according to manufacturer instructions, to collect the strain data from six sensors mounted on the distal region of the tibia. According to previous studies, ground reaction forces to the ankle joint during daily activities are about the same as body weight (BW) to 1.5 times of BW (Michael et al., 2008). Therefore, a maximum of $1,000 \mathrm{~N}$ was exerted on the tibia, which was sufficient to obtain data from the strain gauges, and was also safe enough to prevent bone damage. After each loading phase, unloading data were recorded subsequently for comparing their patterns to make sure that the tests are reliable.

\subsection{Computational model}

In order to generate a 3D model of the ankle, CT data were segmented in MIMICS 10.01 (The Materialise Inc.). Each area, which was automatically selected by the software, was then modified manually, in order to maintain accurate borders and minimise the negative effects related to software threshold and sensitivity in the bony tissue selection procedure (Schileo et al., 2007). The resolution of $0.6 \mathrm{~mm}$ slices from the SIEMENSTM CT scanning device was thin enough to generate reliable and smooth surfaces for the 3D reconstruction procedure (Bagci et al., 2012). After 3D reconstruction, the bones surface should be made smooth, since smoothing operations usually result in loss of some useful information, the optimum level of smoothing is important in order to keep surface details as much as possible. In this study, smoothing was performed on the mask to remove the noise without changing the voxel size, or number of voxels. The minimum iteration was selected for smoothing by a trial and error method. Six bones (tibia, fibula, talus, calcaneus, navicular, and cuboid) were generated separately as 3D shells in MIMICS, and then exported to commercially available software CATIA V19 (Dassault Systems). Using CATIA uneven surfaces that have been generated from bad segmentation were removed to smooth the noisy surfaces. The solid bodies resulting from CATIA were then exported for each bone specimen. Articular cartilage was modeled as a non-uniform layer extruded part in the joint space between tibia and talus (Schmitt et al., 2001). FE modelling was performed using a commercially available code, ANSYS WORKBENCH V.13 (ANSYS, PA, USA). All six modelled bones were imported into the Design Modeler module of ANSYS WORKBENCH with an IGS file format, and assembled into an integrated joint, corresponding to CT images arrangement. In the computational model, bones keep their relations on the neutral position of the foot, the same as its situation at imaging time. Each bone was defined as a flexible body in the software (Anderson et al., 2010). In this study, quasi-physiologic loading parameters including periodic loading, as well as time-dependent and viscoelastic properties have not been considered (Anderson et al., 2007; Chegini et al., 2009). In order to achieve more accurate results from the FEM, the tibia was considered as a hollow shaft with non-uniform thickness, and, for the sake of simplicity, cancellous bone was removed from the CT images. Tibia was modelled as a cortical bone with orthotropic linear elastic material properties (Table 1). All other bones 
were assumed to behave as linear elastic and isotropic materials (Elastic modulus $=7300$ $\mathrm{MPa}$ and Poisson's ratio $=0.3$ ) (Asgari et al., 2004; Speirs et al., 2007; Taylor et al., 2002; Ionescu et al., 2003; $\mathrm{Ng}$ et al., 2012). Articular cartilage was also considered as a linear elastic and isotropic material (elastic modulus $=12 \mathrm{MPa}$, Poisson's ratio $=0.42$ ) (Anderson et al., 2007; Hsu et al., 2008). In order to model contact surface of the joints, all the joints were constrained as bonded contact regions in the software.

Table 1 Mechanical properties of human tibia

\begin{tabular}{lccccccccc}
\hline $\begin{array}{l}\text { Material } \\
\text { property }\end{array}$ & $E_{1}(G P a)$ & $E_{2}(G P a)$ & $E_{3}(G P a)$ & $G_{12}(G P a)$ & $G_{13}(G P a)$ & $G_{23}(G P a)$ & $v_{12}$ & $v_{13}$ & $v_{23}$ \\
\hline $\begin{array}{l}\text { Human } \\
\text { tibia }\end{array}$ & 6.91 & 8.51 & 18.4 & 2.41 & 3.56 & 4.91 & 0.49 & 0.12 & 0.14 \\
\hline
\end{tabular}

Note: A hollow shape model was assumed for tibia.

Source: Ionescu et al. (2003)

Figure 5 FEM assembly (see online version for colours)

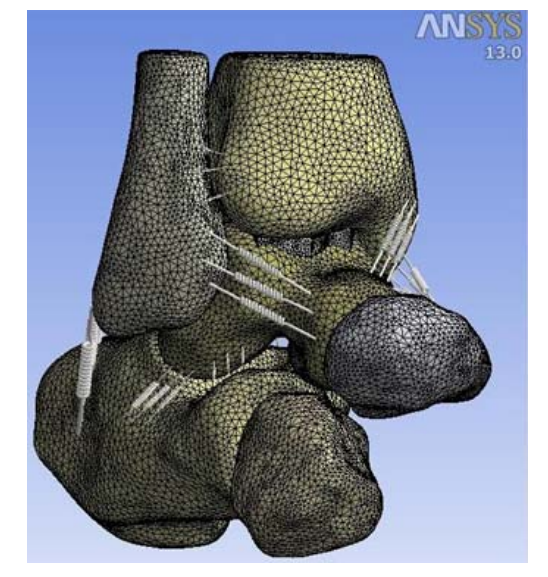

Notes: 3D SOLID187 elements in ANSYS were used for the purpose of mesh generation of all bone parts. Nonlinear spring elements, COMBIN39, were used for modeling the ligaments surrounding the joint. Ligaments were considered as tension spring, which carry no compressive load.

3D solid187 elements were used for meshing the model (Figure 5). The size of the mesh was considered to be a minimum of $1 \mathrm{~mm}$ and maximum of $3 \mathrm{~mm}$ in order to cover all curvatures. TARGET170 and CONTACT174 elements in ANSYS were used for meshing target and contact surfaces, respectively. According to the literature, force transmission at the distal tibia is dominantly passed through the circumference of the bone, i.e., on the cortical rim of distal tibia (Hintermann, 2004). In other words, there is almost no force transmission through the centre of distal tibia (Hintermann, 2004) (Figures 6 and 7). A total of 14 ligaments were placed surrounding the ankle joint (List, 2009), and in order to avoid stress concentration effect, each ligament was modelled by three springs. Nonlinear spring elements (COMBIN39 in ANSYS) were used for modeling ligaments around the joint. In the computational model, element properties of the ligaments defined as tensiononly, where the spring stiffness was considered to be $50 \mathrm{~N} / \mathrm{mm}$ (Anderson et al., 2005). Spatial arrangements of the ligaments were applied according to their anatomical 
positions (Figure 5) (Hintermann, 2004). In this study, for the sake of simplicity, muscle and tendons were excluded. Therefore, the reaction forces are purely transferred via joint surfaces (Anderson et al., 2008).

Figure 6 Distal surface of the tibia (see online version for colours)

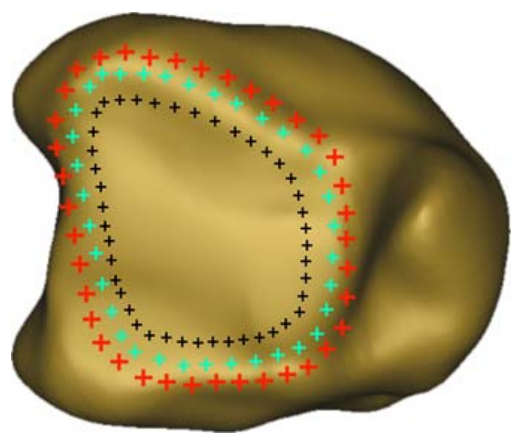

Notes: Force transmission at the distal tibia occurs mainly through the cortical rim. The place of load exertion and its intensity are assigned by coloured $(+)$ sign. Red signs show high magnitude of load transfer on the joint surface, green and black signs show medium and lower magnitudes of load transmission, respectively.

Source: Hintermann (2004)

Figure 7 Tibia modelled as a hollow shaft (see online version for colours)

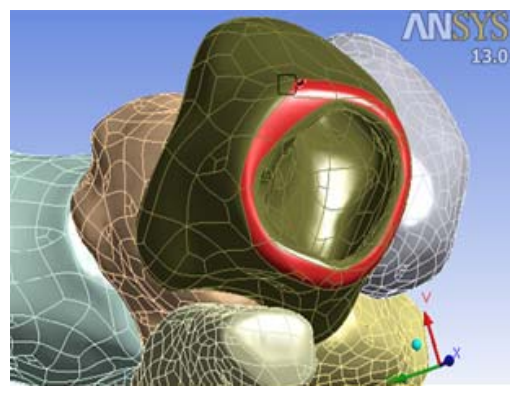

Notes: Load was applied on circumference of the proximal tibia (coloured red area).

Using the theory of three axes strain gauges, the magnitudes of principal strains were calculated. The maximum and minimum strains can be calculated by solving equations (1) and (2) (Young and Budynas, 2002).

$$
\begin{aligned}
& \varepsilon_{\text {Max.principal strain }}=\frac{1}{2}\left[\varepsilon_{1}+\varepsilon_{2} \sqrt{2\left\{\left(\varepsilon_{1}-\varepsilon_{3}\right)^{2}+\left(\varepsilon_{2}-\varepsilon_{3}\right)^{2}\right\}}\right] \\
& \varepsilon_{\text {Min.principal strain }}=\frac{1}{2}\left[\varepsilon_{1}+\varepsilon_{2} \sqrt{2\left\{\left(\varepsilon_{1}-\varepsilon_{3}\right)^{2}+\left(\varepsilon_{2}-\varepsilon_{3}\right)^{2}\right\}}\right]
\end{aligned}
$$

where $\varepsilon_{1}, \varepsilon_{2}, \varepsilon_{3}$ are three strain values which were recorded from three axes of rosette strain gauges, respectively.

Von Mises criterion [equation (3)] was established in order to compare the strains calculated in our FE model with experimental data from the strain gauges given by the following relationship (Completo et al., 2007): 


$$
\varepsilon_{\text {Von Mises }}=\sqrt{\begin{array}{l}
\left(\varepsilon_{\text {Max.Principal strain }}\right)^{2}+\left(\varepsilon_{\text {Min.Principal strain }}\right)^{2} \\
-\varepsilon_{\text {Max.Principal strain }} * \varepsilon_{\text {Min.Principal strain }}
\end{array}}
$$

\section{Results}

Using Von Mises strains around the tibia as metrics of convergence, a mesh of approximately 350,000 elements for the whole tibia was enough to assure a converged FE solution. Computation times (Intel(R) Core(TM) 2 Duel CPU T9550 (64 bit) system; 4 GB RAM) ranged from 81 seconds for 33,935 elements to nearly 2,027 seconds for 653,849 elements (1,184 seconds for the converged FE solution).

Figure 8 Strains logged during loading and unloading in 40 seconds from medial and lateral side of tibia (see online version for colours)

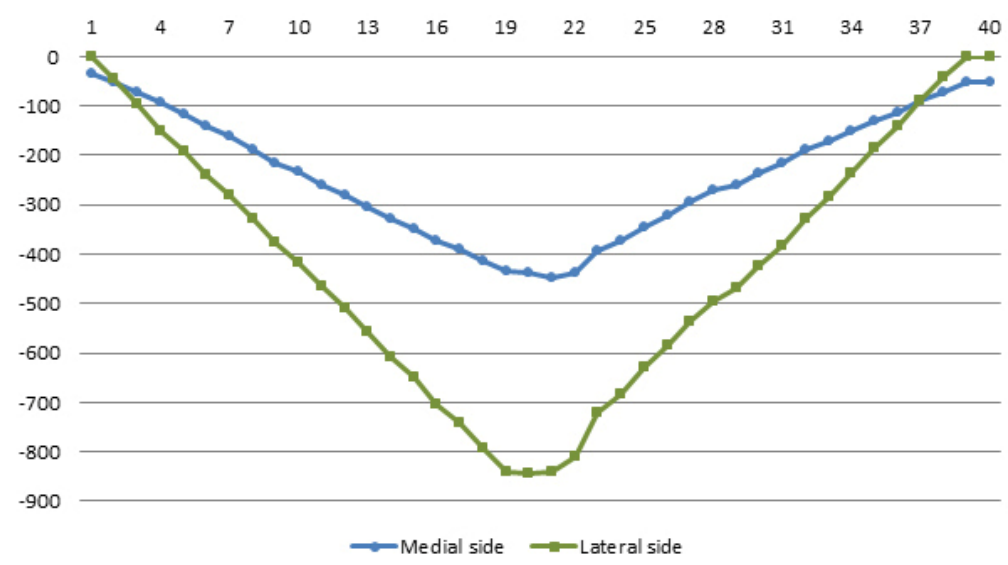

Experimental results for medial and lateral strain gauges are shown in Figure 8. In this figure, only strains along the main axis of the strain gauge (the axis parallel with the longitudinal axis of tibia) are shown. The data shown in this figure demonstrate measured strains during loading and unloading. As it was expected, based on the linear elastic behaviour of the cortical bone, the trend of both loading and unloading are similar (Cordey and Gautier, 1999). Thus, this acceptable behaviour can be deemed as a logical generalisation to all other strain gauges. As it can be seen in this figure, the load was just compressive due to negative strains registered in experiment. Von Mises strains can be seen in Table 2 for both of experimental data [calculated by equation (3)] and finite element in neutral position of the foot. In this table, total strain for each location of the gauges was considered by the differences between the maximum (when external load is $1,000 \mathrm{~N}$ ) and minimum strain under loading. The differences between strain values in the opposite sides of the distal tibia, i.e., lateral versus medial, and anterior versus posterior cause the bending moment in the bone whereby, the stress distribution at the contact surface would be changed consequences to loading conditions. Figure 9 shows the strains around the tibia which were recorded by the strain gauges and demonstrate the same trend compare to the FE model strain values. Considering previous in vivo and in vitro 
studies on tibia strains under same loading conditions, the results are in a fair range at the same place of the gauges (Yang et al., 2011; Completo et al., 2007).

Table 2 Strain gauge data from the experiment and FEM in the neutral position of the foot under a 1,000 $\mathrm{N}$ load (minus sign shows compressive load

\begin{tabular}{|c|c|c|c|c|c|c|c|}
\hline \multicolumn{7}{|c|}{ Experiment } & \multirow{2}{*}{$\begin{array}{c}F E M \\
\varepsilon_{\text {von Mises }} \\
(\mu \text { strain) }\end{array}$} \\
\hline & $\begin{array}{c}\varepsilon_{\text {Axis }(1)} \\
\text { (ustrain) }\end{array}$ & $\begin{array}{c}\varepsilon_{\text {Axis }(2)} \\
\text { (ustrain) }\end{array}$ & $\begin{array}{c}\varepsilon_{A x i s(3)} \\
\text { (ustrain) }\end{array}$ & $\begin{array}{c}\varepsilon_{\max .} \\
\text { principal } \\
\text { strain } \\
(\mu \text { strain) }\end{array}$ & $\begin{array}{c}\varepsilon_{\text {min. }} \\
\text { principal } \\
\text { strain } \\
\text { (ustrain) }\end{array}$ & $\begin{array}{l}\varepsilon_{\text {von Mises }} \\
\text { (ustrain) }\end{array}$ & \\
\hline Medial & -414 & 208 & -218 & 229 & -435 & 584.2 & 293 \\
\hline Antromedial & -528 & 324 & -324 & 378 & -582 & 837.6 & 560 \\
\hline Antrolateral & -334 & 381 & 178 & 413 & -366 & 675.0 & 345 \\
\hline Lateral & -843 & 334 & -143 & 344 & -853 & $1,067.4$ & 894 \\
\hline Postrolateral & -52 & 82 & 13 & 82 & -52 & 117.0 & 70 \\
\hline Postromedial & -282 & 356 & 46 & 356 & -282 & 553.8 & 261 \\
\hline
\end{tabular}

Notes: The three elements of strain gauges: $\varepsilon_{1}$ (1st axis of the strain gauge), $\varepsilon_{2}$ (2nd axis, perpendicular to the 1 st axis), $\varepsilon_{3}$ (3rd axis, makes an angle of $45^{\circ}$ with respect to the 1st or 2nd axis). The principal and von Mises strains were calculated using equations (1) to (3).

Figure 9 Von Mises strain values for the computational model, and those collected by strain gauges when an axial load of $1,000 \mathrm{~N}$ was applied to the proximal surface of tibia (see online version for colours)

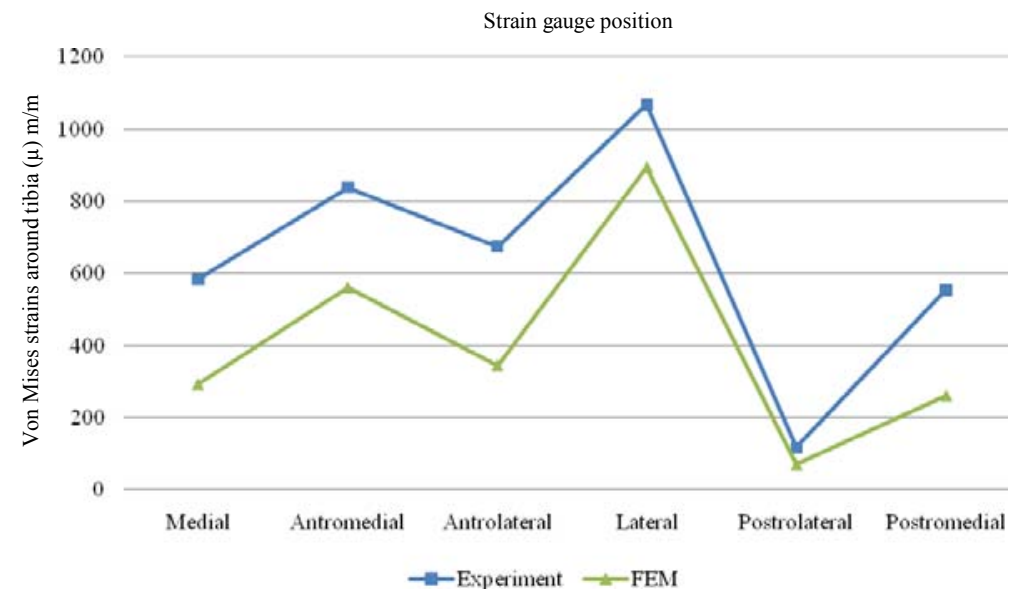

The stress distribution at the contact surface of distal end of the tibia, which was computed by the FEM can be seen in Figure 10. This figure shows that stress is concentrated in anterior, and anterolateral regions of the joint. As it can be seen in Figure 10, most of the joint surface experiences a stress of less than $2 \mathrm{MPa}$ and the maximum stress occurs in antrolateral side (about 3.9 MPa). 
Figure 10 Bottom view of the tibia: Von Mises stress plots for tibiotalar joint determined by a FE model showing stress distributions on the contact area (see online version for colours)

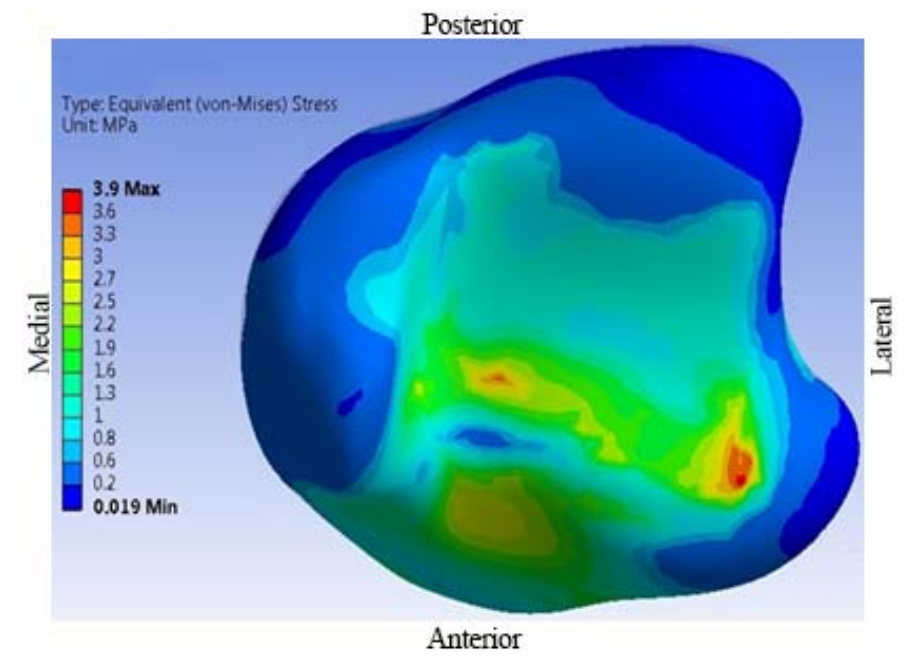

Notes: Stress contours show that the concentration of stress can be found in the anterior, and anterolateral regions of the joint.

\section{Discussion and conclusions}

Through direct comparison between experiment and strains calculated by the FEM, the computational model was verified, with the ultimate goal of investigating low-invasively the stress distribution on tibiotalar joint surface. In this study, first by mounting strain gauges around the tibia, strain distribution under axial load was obtained in different positions of the foot (see the appendix). The data shown in Figure 8 indicate that the attachment of the strain gauges was properly done, and correct data were logged because of the similarity in trend of loading and unloading data (Cordey and Gautier, 1999; Yang et al., 2011). The data collected by strain gauges can help understand how load transmission was done throughout the ankle in different positions of the foot. In the second phase, for evaluating the stress distribution pattern on the tibiotalar joint surface, a FEM was developed and validated using the data collected in the first step of the research.

A strong correlation between the FE analysis and strain gauges data confirmed the validity of our FE model $(\mathrm{R}=0.94)$. This validation paved the way for calculation of the contact stress distributions across the articular surface of the ankle joint using the validated FEMs. The stress distribution on the joint surface, Figure 10, well agreed with some prior studies, such as Anderson et al. (2007) (maximum contact stress about $4 \mathrm{MPa}$ in antrolateral of the ankle joint surface), Michael et al. (2008), and Tochigi et al. (2006), in which they used pressure transducers at the ankle joint to investigates the joint surface stress distribution. The contact surface involved in load transferring resulted from this study also is in agreement with a study in which magnetic tracking system was employed to investigate the ankle joint contact surface (Hideji et al., 1998). 
Strain gauge data (Figure 9) indicate that the ankle joint can be considered as an integration of several discrete surfaces, in agreement with Hideji et al.'s (1998) findings. Considerable variation in the stress distributions and contact areas of the joint will be resulted by altering the boundary conditions, and/or ankle position in the FEM, similar to the recorded strains in experiment while changing joint position (Figure 11). This finding implies that the contact area is sensitive to any instability of the joint. Any factors that alter the contact areas can cause considerable variations in the results of load transferring, and consequently in stress distribution on contact area. In a study by Calhoun and co-workers, a reduction in contact area has been shown for an ankle in inversion, eversion, and plantar flexion, whereas they report an increase in contact area for dorsiflexion (Calhoun et al., 1994). They noted that inversion increases the medial facet contact area, and eversion increases the lateral facet contact area, in agreement with what was found in this study (see Tables 3 to 6 in the Appendix). Strains obtained from other than neutral position of the foot are shown in Tables 3 to 6 in the Appendix. Data appeared in these tables can be used to find qualitative relations between strain, contact area, and stress distributions. According to the strain gauges' data, and by comparing with the neutral position, when the foot moves towards plantar flexion, higher magnitudes of strains adjacent to the joint were shifted from medial, anterolateral, and lateral sides to posterolateral, posteromedial, and anteromedial sides of the joint (see Table 3). The mentioned strains were transferred from the medial and anteromedial to lateral, and anterolateral sides in dorsiflexion (see Table 4). Also, in inversion, higher strains were transferred from posteromedial to anteromedial region (see Table 5). Finally, this change was occurred from the medial and anteromedial to the lateral, anterolateral, posteromedial, and posterolateral regions in eversion (see Table 6) (see Figure 11).

Figure 11 Strain values compared to neutral position (base line) collected by the strain gauges mounted around the distal tibia for different positions of the ankle (see online version for colours)

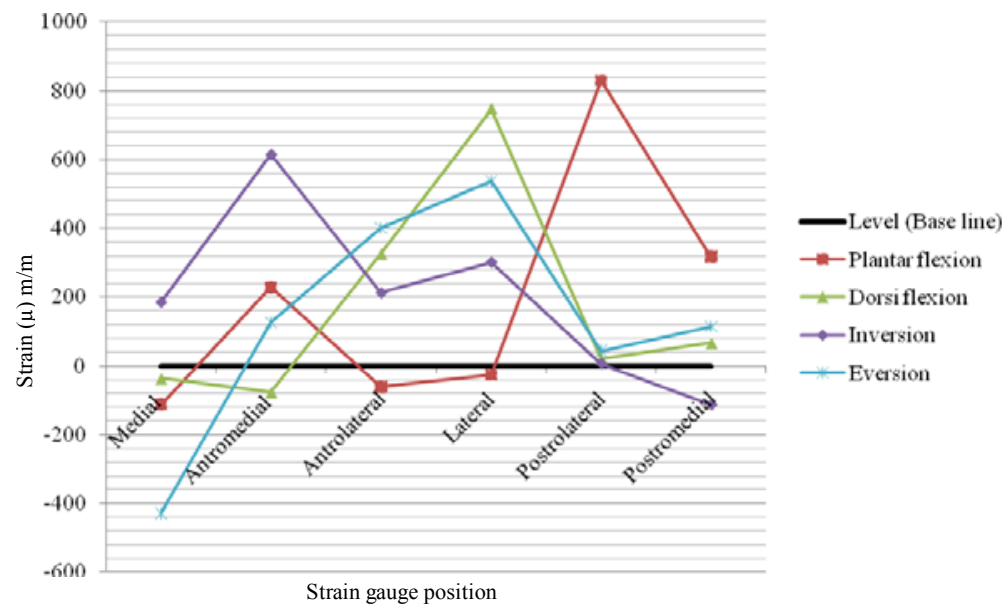

There were some limitations in this study, such as: the cadaver foot was cut from metatarsal bones because of some ethical constraints, thus metatarsal joints were excluded; and spongy bone, muscle and tendons were disregarded in the FE model. Since just static load on the ankle joint was utilised in this study, future research is better to 
consider dynamic loads in order to more realistically model the gait cycle or other dynamic activities. In future analyses, it is also better to include the effects of ligaments, tendons, and muscles, as they very likely play important roles in the stability of the ankle joint under dynamic loads.

\section{Acknowledgements}

The authors acknowledge the support of the Iran National Science and Foundation (INSF), Iranian tissue Bank Center (ITB), and Amirkabir University of Technology.

\section{References}

Alkjaer, T., Simonsen, E.B. and Dyhre-Poulsen, P. (2001) 'Comparison of inverse dynamics calculated by two- and three-dimensional models during walking', Gait Posture, Vol. 13, No. 2, pp.73-77.

Anderson, A.E., Ellis, B.J., Maas, S.A. and Weiss, J.A. (2010) 'Effects of idealized joint geometry on finite element predictions of cartilage contact stresses in the hip', J. Biomechanics, Vol. 43, No. 7, pp.1351-1357.

Anderson, A.E., Ellis, B.J., Maas, S.A., Peters, C.L. and Weiss, J.A. (2008) 'Validation of finite element predictions of cartilage contact pressure in the human hip joint', J. Biomechanics, Vol. 130, No. 5, pp.1-25.

Anderson, D.D., Deshpande, B.R., Daniel, T.E. and Baratz, M.E. (2005) 'A three-dimensional finite element model of the radiocarpal joint: distal radius fracture step-off and stress transfer', Iowa Orthopaedics Journal, Vol. 25, pp.108-117.

Anderson, D.D., Goldsworthy, J.K., Li, W., Rudert, M.J., Tochigi, Y. and Brown, T.D. (2007) 'Physical validation of a patient-specific contact finite element model of the ankle', $J$. Biomechanics, Vol. 40, No. 8, pp.1662-1669.

Arbabi, E., Boulic, R. and Thalmann, D. (2007) 'A fast method for finding range of motion in the human joints', Conf. Proc. IEEE Eng. Med. Biol. Soc., pp.5079-5082.

Asgari, S.A., Hamouda, A.M.S., Mansor, J.B., Singh, H., Mahdi, E., Wirza, R. and Prakash, B. (2004) 'Finite element modeling of a generic stem less hip implant design in comparison with conventional hip implants', Finite Element in Analysis and Design, Vol. 40, No. 15, pp.2027-2047.

Ateshian, G.A. (2009) 'The role of interstitial fluid pressurization in articular cartilage lubrication', J. Biomechanics, Vol. 42, No. 9, pp.1163-1176.

Bagci, U., Chen, X. and Udupa, J.K. (2012) 'Hierarchical scale-based multi-object recognition of 3-D anatomical structures', IEEE Trans. Med. Imaging, Vol. 31, No. 3, pp.777-789.

Beaudoin, A.J., Fiore, S.M., Krause, W.R. and Adelaar, R.S. (1991) 'Effect of isolated talocalcaneal fusion on contact in the ankle and talonavicular joints', Foot Ankle, Vol. 12, No. 1, pp.19-25.

Brand, R.A., Pedersen, D.R., Davy, D.T., Kotzar, G.M., Heiple, K.G. and Goldberg, V.M. (1994) 'Comparison of hip force calculations and measurements in the same patient', J. Arthroplasty, Vol. 9, No. 1, pp.45-51.

Calhoun, J.H., Li, F., Ledbetter, B.R. and Viegas, S.F. (1994) 'A comprehensive study of pressure distribution in the ankle joint with inversion and eversion', J. Foot Ankle Int., Vol. 15, No. 3, pp.125-133.

Caligaris, M. and Ateshian, G.A. (2008) 'Effects of sustained interstitial fluid pressurization under migrating contact area, and boundary lubrication by synovial fluid, on cartilage friction', $J$. Osteoarthritis and Cartilage, Vol. 16, No. 10, pp.1220-1227. 
Chegini, S., Beck, M. and Ferguson, S.J. (2009) 'The effects of impingement and dysplasia on stress distributions in the hip joint during sitting and walking: a finite element analysis', $J$. Orthop. Res., Vol. 27, No. 2, pp.195-201.

Completo, A., Fonseca, F. and Simões, J.A. (2007) 'Finite element and experimental cortex strains of the intact and implanted tibia', J. Biomechanical Engineering, Vol. 129, No. 5, pp.791-797.

Cordey, J. and Gautier, E. (1999) 'Strain gauges used in the mechanical testing of bones Part III Strain analysis, graphic determination of the neutral axis', J. Injury, Int. J. Care Injured, Vol. 30, No. 1, p.SA21-5.

Gilles, B., Moccozet, L. and Magnenat-Thalmann, N. (2006) 'Anatomical modeling of the musculoskeletal system from MRI', Med. Image Comput. Comput. Assist. Interv., Vol. 9, No. 1, pp.289-296.

Gíslason, K.M., Stansfield, B. and Nash, H.D. (2010) 'Finite element model creation and stability considerations of complex biological articulation', The Human Wrist Joint, Vol. 32, No. 5, pp.523-531.

Goh, J., Hin, E.L., Joo, E.A., Bayon, P. and Pho, R. (1992) 'Biomechanical study on the load-bearing characteristics of the fibula and the effects of fibular resection', J. Clinical Orthopaedics \& Related Research, Vol. 279, pp.223-228.

Goreham-Voss, C.M., McKinley, T.O. and Brown, T.D. (2007) 'A finite element exploration of cartilage stress near an articular incongruity during unstable motion', J. Biomechanics, Vol. 40, No. 15, pp.3438-3447.

Greene, G.W., Zappone, B., Zhao, B, Söderman, O, Topgaard, D. and Rata, G. (2008) 'Changes in pore morphology and fluid transport in compressed articular cartilage and the implications for joint lubrication', J. Biomaterials, Vol. 29, No. 33, pp.4455-4462.

Hideji, K., Harold, B.K., Zong-Ping, L. and Kai-Nan, A. (1998) 'Measurement of surface contact area of the ankle joint', J. Clinical Biomechanics, Vol. 13, Nos. 4-5, pp.365-370.

Hintermann, B. (2004) Total Ankle Arthroplasty, pp.25-42, Springer, Wien.

Hsu, Y.C., Gung, Y.W., Shih, S.L., Feng, C.K., Wei, S.H., Yu, C.H. and Chen, C.S. (2008) 'Using an optimization approach to design an insole for lowering plantar fascia stress - a finite element study', Annals Biomed. Eng., Vol. 36, No. 8, pp.1345-1352.

Ionescu, I., Conway, T., Schonning, A., Almutairi, M. and Nicholson, D.W. (2003) 'Solid modeling and static finite element analysis of the human tibia', Conf. Proc. Bioengineering Conference, Florida.

List, R.B. (2009) Joint Kinematics of Unconstrained Ankle Arthroplasties, pp.19-22, ETH, Zürich.

Macirowski, T., Tepic, S. and Mann, R.W. (1994) 'Cartilage stresses in the human hip joint', $J$. Biomechanics, Vol. 116, No. 1, pp.10-18.

McKinley, T.O., Rudert, M.J., Koos, C.D., Pedersen, R.D., Baer, E.T., Tochigi, Y. and Brown, D.T. (2006) 'Contact stress transients during functional loading of ankle step-off incongruities', J. Biomechanics, Vol. 39, No. 4, pp.617-626.

Michael, J.M., Golshani, A., Gargac, S. and Goswami, T. (2008) 'Biomechanics of the ankle joint and clinical outcomes of total ankle replacement', J. Mechanical Behavior of Biomedical Materials, Vol. 1, No. 4, pp.276-294.

Ng, K.C., Rouhi, G., Lamontagne, M.E. and Beaulé, P. (2012) 'Finite element analysis examining the effects of Cam FAI on hip joint mechanical loading using subject-specific geometries during standing and maximum squat', Hospital for Special Surgery Journal (HSSJ), Vol. 8, No. 3, pp.206-212.

Ringleb, S.I., Udupa, J.K., Siegler, S., Imhauser, C.W., Hirsch, B.E., Liu, J., Odhner, D., Okereke, E. and Roach, N. (2005) 'The effect of ankle ligament damage and surgical reconstructions on the mechanics of the ankle and subtalar joints revealed by three-dimensional stress MRI', $J$. Orthopaedic Research, Vol. 23, No. 4, pp.743-749.

Schileo, E., Taddei, F., Malandrino, A., Cristofolini, L. and Viceconti, M. (2007) 'Subject-specific finite element models can accurately predict strain levels in long bones', J. Biomechanics, Vol. 40, No. 13, pp.2982-2989. 
Schmitt, J., Meiforth, J. and Lengsfeld, M. (2001) 'Influence of cartilage cap modeling on FEM simulation of femoral head stress', J. Biomed. Tech. (Berl), Vol. 46, Nos. 1-2, pp.29-33.

Söderdahl, G., Tammik, C., Remberger, M. and Ringdén, O. (1998) 'Cadaveric bone marrow and spleen cells for transplantation', J. Bone Marrow Transplant, Vol. 21, No. 1, pp.79-84.

Speirs, A.D., Heller, M.O., Duda, G.N. and Taylor, W.R. (2007) 'Physiologically based boundary conditions in finite element modeling', J. Biomechanics, Vol. 40, No. 10, pp.2318-2323.

Taylor, W.R., Roland, E., Ploeg, H., Hertig, D., Klabunde, R., Warner, M.D., Hobatho, M.C., Rakotomanana, L. and Clift, S.E. (2002) 'Determination of orthotropic bone elastic constants using FEA and modal analysis', J. Biomechanics, Vol. 35, No. 6, pp.767-773.

Tochigi, B., Rudert, M.J., Saltzman, C.L., Amendola, A. and Brown, T.D. (2006) 'Contribution of articular surface geometry to ankle stabilization', J. Bone \& Joint Surgery, Vol. 12, No. 12, pp.2704-2713.

Von Eisenhart-Rothe, R., Eckstein, F., Muller-Gerbl, M., Landgraf, J., Rock, C. and Putz, R. (1997) 'Direct comparison of contact areas, contact stress and subchondral mineralization in human hip joint specimens', Anat. Embryol (Berl)., Vol. 195, No. 3, pp.279-288.

Yang, P.F., Brüggemann, G.P. and Rittweger, J. (2011) 'What do we currently know from in vivo bone strain measurements in humans?', J. Musculoskelet Neuronal Interact, Vol. 11, No. 1, pp.8-20.

Young, W.C. and Budynas, R.G. (2002) Roark's Formulas for Stress and Strain, 7th ed., McGraw-Hill, New York.

\section{Appendix}

Table 3 Strain gauges data from the experiment in plantar flexion under 1,000 $\mathrm{N}$ of load (minus sign shows compressive loading)

\begin{tabular}{lcccccc}
\hline \multicolumn{7}{c}{ Experiment } \\
\hline & $\begin{array}{c}\varepsilon_{\text {Axis }(1)} \\
(\mu \text { strain) }\end{array}$ & $\begin{array}{c}\varepsilon_{\text {Axis }(2)} \\
(\mu \text { strain) }\end{array}$ & $\begin{array}{c}\varepsilon_{\text {Axis }(3)} \\
(\mu \text { strain) }\end{array}$ & $\begin{array}{c}\varepsilon_{\text {max. principal strain }} \\
(\mu \text { strain) }\end{array}$ & $\begin{array}{c}\varepsilon_{\text {min. principal strain }} \\
(\mu \text { strain })\end{array}$ & $\begin{array}{c}\varepsilon_{\text {von Mises }} \\
(\mu \text { strain })\end{array}$ \\
\hline Medial & -290 & 214 & 65 & 234 & -310 & 472.6 \\
Antromedial & -650 & 445 & -377 & 510 & -715 & $1,065.8$ \\
Antrolateral & -314 & 344 & 197 & 391 & -316 & 613.4 \\
Lateral & -836 & 311 & -360 & 319 & -844 & $1,040.8$ \\
Postrolateral & -675 & 345 & 8 & 374 & -704 & 948.0 \\
Postromedial & -630 & 318 & -15 & 339 & -651 & 871.4 \\
\hline
\end{tabular}

Notes: 1 (1staxis of the strain gauge); 2 (2nd axis, perpendicular to the 1st axis); 3 (3rd axis, makes an angle of $45^{\circ}$ with respect to the 1 st or 2 nd axis) are the three elements of strain gauges. The principal and von Mises strains can be calculated using equations (1) to (3). 
Table 4 Strain gauge data from the experiment in dorsiflexion under 1,000 $\mathrm{N}$ of load (minus sign shows compressive loading)

\begin{tabular}{lcccccc}
\hline \multicolumn{7}{c}{ Experiment } \\
\hline & $\begin{array}{c}\varepsilon_{\text {Axis }(1)} \\
(\mu \text { strain })\end{array}$ & $\begin{array}{c}\varepsilon_{\text {Axis }(2)} \\
(\mu \text { strain })\end{array}$ & $\begin{array}{c}\varepsilon_{\text {Axis }(3)} \\
(\mu \text { strain })\end{array}$ & $\begin{array}{c}\varepsilon_{\text {max. principal strain }} \\
(\mu \text { strain })\end{array}$ & $\begin{array}{c}\varepsilon_{\text {min. principal strain }} \\
(\mu \text { strain })\end{array}$ & $\begin{array}{c}\varepsilon_{\text {von Mises }} \\
(\mu \text { strain })\end{array}$ \\
\hline Medial & -288 & 156 & 156 & 248 & -380 & 547.9 \\
Antromedial & -381 & 240 & 238 & 367 & -508 & 761.0 \\
Antrolateral & -432 & 384 & 384 & 553 & -601 & 999.7 \\
Lateral & $-1,051$ & 407 & 407 & 709 & $-1,353$ & $1,814.5$ \\
Postrolateral & -40 & 67 & 72 & 93 & -66 & 138.4 \\
Postromedial & -253 & 253 & 253 & 358 & -358 & 620.1 \\
\hline
\end{tabular}

Notes: 1 (1st axis of the strain gauge); 2 (2nd axis, perpendicular to the 1st axis);

3 (3rd axis, makes an angle of $45^{\circ}$ with respect to the 1 st or 2 nd axis) are the three elements of strain gauges. The principal and von Mises strains can be calculated using equations (1) to (3).

Table 5 Strain gauge data from the experiment in inversion under $1,000 \mathrm{~N}$ of load (minus sign shows compressive loading)

\begin{tabular}{lcccccc}
\hline \multicolumn{7}{c}{ Experiment } \\
\hline & $\begin{array}{c}\varepsilon_{\text {Axis }(1)} \\
(\mu \text { strain) })\end{array}$ & $\begin{array}{c}\varepsilon_{\text {Axis }(2)} \\
(\mu \text { strain })\end{array}$ & $\begin{array}{c}\varepsilon_{\text {Axis }(3)} \\
(\mu \text { strain })\end{array}$ & $\begin{array}{c}\varepsilon_{\text {max. principal strain }} \\
(\mu \text { strain })\end{array}$ & $\begin{array}{c}\varepsilon_{\text {min. principal strain }} \\
(\mu \text { strain })\end{array}$ & $\begin{array}{c}\varepsilon_{\text {von Mises }} \\
(\mu \text { strain })\end{array}$ \\
\hline Medial & -406 & 218 & 218 & 347 & -535 & 769.6 \\
Antromedial & -737 & 469 & 443 & 701 & -969 & $1,452.5$ \\
Antrolateral & -354 & 397 & 371 & 534 & -491 & 887.9 \\
Lateral & -810 & 288 & 288 & 515 & $-1,037$ & $1,369.2$ \\
Postrolateral & -29 & 68 & 70 & 90 & -51 & 123.7 \\
Postromedial & -86 & 267 & 267 & 340 & -159 & 441.5 \\
\hline
\end{tabular}

Notes: $\varepsilon_{1}$ (1st axis of the strain gauge), $\varepsilon_{2}$ (2nd axis, perpendicular to the $1 \mathrm{st}$ axis), $\varepsilon_{3}$ (3rd axis, makes an angle of $45^{\circ}$ with respect to the 1 st or 2 nd axis) are the three elements of strain gauges. The principal and von Mises strains can be calculated using equations (1) to (3).

Table 6 Strain gauge data from the experiment in eversion under 1,000 N of load (minus sign shows compressive loading)

\begin{tabular}{lcccccc}
\hline \multicolumn{7}{c}{ Experiment } \\
\hline & $\begin{array}{c}\varepsilon_{\text {Axis(1) }} \\
(\mu \text { strain) }\end{array}$ & $\begin{array}{c}\varepsilon_{\text {Axis(2) }} \\
(\mu \text { strain) }\end{array}$ & $\begin{array}{c}\varepsilon_{\text {Axis }(3)} \\
(\mu \text { strain) }\end{array}$ & $\begin{array}{c}\varepsilon_{\text {max. principal strain }} \\
(\mu \text { strain) }\end{array}$ & $\begin{array}{c}\varepsilon_{\text {min. principal strain }} \\
(\mu \text { strain) }\end{array}$ & $\begin{array}{c}\varepsilon_{\text {von Mises }} \\
(\mu \text { strain) }\end{array}$ \\
\hline Medial & 149 & 162 & 157 & 162 & 149 & 155.9 \\
Antromedial & -365 & 284 & -492 & 516 & -597 & 964.7 \\
Antrolateral & -587 & 640 & 120 & 647 & -594 & $1,075.1$ \\
Lateral & $-1,257$ & 494 & -171 & 519 & $-1,282$ & $1,605.7$ \\
Postrolateral & -86 & 90 & -28 & 95 & -91 & 161.1 \\
Postromedial & -383 & 356 & -122 & 372 & -399 & 667.8 \\
\hline
\end{tabular}

Notes: 1 (1st axis of the strain gauge); 2 (2nd axis, perpendicular to the 1 st axis); 3 (3rd axis, makes an angle of $45^{\circ}$ with respect to the 1 st or 2 nd axis) are the three elements of strain gauges. The principal and von Mises strains can be calculated using equations (1) to (3). 